\title{
La docencia universitaria como praxis política. Aportes para repensar la formación y el ejercicio profesional de los/as Trabajadores/ as Sociales en el ámbito universitario
}

\section{University teaching as political praxis. Contributions to rethink the training and professional practice of Social Workers in the university field}

\author{
Silvana Martínez ${ }^{a}$
}

\section{Resumen}

El presente artículo pretende ser un aportar a la reflexión en torno a la importancia del ejercicio de la docencia como ejercicio profesional en el marco de la Universidad Pública inscripta siempre en condiciones históricas que la atraviesan y la configuran. Las prácticas docentes también siempre se inscriben en marcos institucionales. En este caso, me referiré específicamente a la Universidad Pública Argentina, no sólo porque creo que es uno de los ámbitos privilegiados de la sociedad, sino, además, porque es mi ámbito de formación y de ejercicio profesional. Asimismo, me referiré brevemente a las implicancias de la práctica de enseñanza-aprendizaje como práctica política y ética en la formación de Trabajadores/as Sociales. Por último, argumentaré por qué considero que la docencia forma parte del ejercicio profesional.

Palabras clave: docencia universitaria, formación profesional, trabajo social.

\begin{abstract}
This article aims to be a contribution to the reflection on the importance of teaching as a professional practice within the framework of the Public University always enrolled in historical conditions that cross and configure it. Teaching practices also always fall within institutional frameworks. In this case, I will refer specifically to the Argentinian Public University, not only because I believe it is one of the privileged areas of society, but also because it is my field of training and professional practice. I will also briefly refer to the implications of the teaching-learning practice as a political and ethical practice in the formation of Social Workers. Finally, I will argue why I consider teaching to be part of professional practice.
\end{abstract}

a Universidad Nacional de Misiones (UNaM), Argentina.

Correspondencia a: silvanamartinezts@gmail.com

Recibido:

17 octubre 2018

Aceptado:

10 diciembre 2018

Artículo publicado en acceso abierto bajo la Licencia Creative Commons.

\section{(c) (i)}

Cita:

Martínez, S. (2018). La docencia universitaria como praxis política. Aportes para repensar la formación y el ejercicio profesional de los/ as Trabajadores/as Sociales en el ámbito universitario. Kera Yvoty: reflexiones sobre la cuestión social, 3, 86-93.

Keywords: university teaching, professional training, social work. 


\section{Introducción. Las Universidades Públicas y la Política}

En el devenir histórico, las Universidades siempre constituyeron ámbitos privilegiados de conocimiento y formación y respondieron a diversos intereses político-ideológicos y económicos en distintos momentos históricos. Es decir, siempre se vincularon al poder y ejercieron poder e influencia, basados precisamente en el saber y en el prestigio de quienes producen y distribuyen conocimientos. Si bien es un poder simbólico, siempre se encarnó en intereses político-ideológicos y económicos muy concretos.

Asimismo, las Universidades siempre fueron instrumentos privilegiados de liberación y emancipación, pero también de opresión y dominación. Esto depende -en general- de para qué y para quién se ejerce el poder y, en el caso de las Universidades, del Proyecto Político-Ideológico encarnado en las mismas, ya que formamos parte de la construcción de un proyecto de país. Es decir, las Universidades no son, ni nunca fueron, neutras ni asépticas. De esto se desprende que la política es un componente constitutivo de las Universidades.

Por otra parte, las Universidades Públicas no sólo forman profesionales, en el mejor de los casos, sino que deberían formar -además- intelectuales y ciudadanos/ as comprometidos/as con su tiempo y su realidad histórica. Para ello, es necesario enfatizar que nuestra tarea es construir sujetos políticos, procurar que nuestros estudiantes se vean a sí mismos como sujetos políticos y, como tales, intenten comprender la realidad nacional, social e institucional, no sólo para interpretar los procesos, sino para transformarlos dentro de sus posibilidades y no ilusoriamente por fuera de ellos. No podemos renunciar a la tarea de formar dirigentes y cuadros políticos, como tampoco lo pueden hacer los Partidos Políticos. No podemos dejar esta tarea en manos del mercado o las empresas, como fue el sueño de quienes gobernaron en los noventa.

Enestemarco, lascátedrasdeberíanser espaciosendondesegenerenlascondiciones no sólo para formar sujetos con habilidades y competencias teórico-metodológicas, sino también sujetos capaces de interpelar, cuestionar, deslegitimar lo establecido, romper las cadenas epistemológicas y pseudocientíficas que no les permiten pensar como sujetos autónomos, utilizar el conocimiento para recrearse a sí mismos, tomar decisiones, buscar el sentido de la profesión y construir poder participando en las organizaciones profesionales, pero también en las organizaciones populares y en los movimientos sociales.

Obviamente, paragenerarestotenemos que comenzar por desandar muchas de nuestras prácticas academicistas y asépticas e incorporar el contexto como punto de partida y referencia permanente del proceso de enseñanza-aprendizaje. Pensar la educación es pensar al ser humano en un tiempo y un espacio concreto, es decir un pensar situado, que no es individual sino colectivo.

Así lo sostenía ya Paulo Freire en la década del 7o, cuando afirmaba que el punto de partida de toda educación es el contexto específico local donde se realiza la práctica educativa, contexto que tiene un carácter relacional, de elementos económicos, sociales, políticos, históricos y culturales, contexto donde tanto los estudiantes como los docentes viven su realidad presente, las huellas de su pasado y el horizonte de su futuro, es decir, un lugar donde viven su propia historia.

\section{La docencia como praxis política}

Coincidiendocon Henry Giroux (2003)

"La enseñanza y el aprendizaje son prácticas profundamente políticas. Son políticas en todos los momentos del circuito: en las condiciones de producción (¿quién produce el saber?, ¿para quién?), en los saberes y en las formas mismas del saber ( $i$ saber de acuerdo con qué plan?, ¿útil para qué?), en su publicación, circulación y accesibilidad, en sus usos profesionales y populares y en sus impactos en la vida cotidiana" (p. 15). 
Como decía, la enseñanza y el aprendizaje son prácticas profundamente políticas. Coincidiendo nuevamente con Paulo Freire, tenemos que reconocer que la práctica educativa no puede ser y, de hecho, no es nunca neutral. No hay educación neutra: la acción educativa, los métodos, los objetivos, siempre obedecen a una visión del ser humano y a un tipo de sociedad por la cual trabajamos.

$\mathrm{Si}$ creemos que el ser humano es capaz de transformar su mundo, entonces la educación será liberadora y transformadora, pero si creemos que la naturaleza del ser humano es la vida fácil y que sólo tiene que acomodarse al orden vigente, "dejar hacer, dejar pasar", entonces la educación será mecánica y domesticadora. Ninguna práctica educativa es neutral: o buscará acomodarse al orden vigente o buscará interpelarlo planteando caminos alternativos.

Pensar la docencia y la educación como una praxis política implica: a) En primer lugar, romper definitivamente con la formación aséptica de profesionales; b) En segundo lugar, implica un giro epistemológico; c) En tercer lugar, implica posicionarse desde un enfoque situado y d) en cuarto lugar, la politización de la formación.

En primer lugar, cuando digo formación aséptica ¿qué quiero decir? Veamos el significado de este término. Aséptico significa "Ausencia de microorganismos infecciosos en los tejidos vivos", y también "Conjunto de técnicas y procedimientos para impedir el acceso de todas las bacterias no deseables a un campo de observación o trabajo" (Enciclopedia Salvat, 1972, p. 305). Llevado al campo de una formación, podemos decir que implica la ausencia de todo elemento que pueda infectar, contaminar o perjudicar el proceso de formación. También podemos decir que se refiere a todos los dispositivos institucionales que impiden el acceso de todo lo no deseable en el proceso de formación.

Una formación aséptica tiende a formar técnicos y no profesionales comprometidos con su tiempo y su realidad histórica, hace hincapié o acentúa más en la instrumentalidad de la profesión, es decir, en el cómo y no favorece la pregunta, la interpelación, el porqué y el para qué. Es una formación aislada de los problemas sociales reales de nuestro pueblo. Es una formación que escinde la realidad de los procesos de enseñanza-aprendizaje. Hay una externalidad del contexto, donde los estudiantes "salen" al campo a estudiar "la realidad" y luego "vuelven" al gabinete a analizar esa realidad. No hay involucramiento con la realidad porque se la ve como algo externo que no debe contaminar o interferir en la formación.

En segundo lugar, en el proceso de formación tenemos que explicitar claramente ¿por qué conocer?, ¿desde dónde conocer? y ¿para qué conocer?, cuestiones estas que nos llevan a las tres tesis propuestas por Boaventura de Sousa Santos (2009) con el nombre de epistemología del Sur. En la primera sostiene el autor que "no habrá justicia social global sin justicia cognitiva global; los procesos de opresión y de explotación, al excluir grupos y prácticas sociales, excluyen también los conocimientos usados por esos grupos para llevar a cabo esas prácticas; a esta dimensión de la exclusión la he llamado epistemicidio" (p. 11).

En la segunda que "el capitalismo y el colonialismo continúan profundamente entrelazados, aunque las forma de articulación hayan variado a lo largo del tiempo...De este modo, la epistemología del Sur, para ser consistentemente anticapitalista ha de ser también anticolonial y viceversa" y en la tercera que "la epistemología del Sur apunta fundamentalmente a prácticas de conocimiento que permitan intensificar la voluntad de transformación social" (Sousa Santos, p. 12-13).

La última afirmación es coincidente con lo que Norman Denzin (2003) propone con el nombre de enfoque performativo en el sentido de crítica social emancipadora, 
cuyo objetivo es la acción política y la transformación social. Se trata de ver el conocimiento como acción y no como algo fijo, estático y cristalizado. Si bien es importante la hermenéutica para comprender e interpretar los significados sociales, no alcanza sólo con comprender una situación problemática si no la utilizamos para producir conocimientos que generen una conciencia emancipatoria (Villarmea, 2001).

Desde el Trabajo Social es necesario no podemos pensar en comprender los procesos de construcción del orden social vigente y mucho menos aun de interpelar el mismo con el fin de transformarlo, sin ubicarnos en una posición epistemológica de justicia cognitiva anticapitalista, anticolonialista y emancipadora de los grupos oprimidosy explotados. Esto implica recuperar en el proceso de formación las voces, los saberes, las prácticas y las experiencias de estos grupos, partiendo de una ruptura de la formación aséptica, avalorativa y neutral y vinculando la misma con la realidad social de nuestros tiempos.

En tercer lugar, tanto en la formación, como en la producción de conocimientos se hace necesario ubicarnos desde un enfoque situado, ¿qué quiero decir con esto? Intelectualesargentinos como Mario Casalla y Rodolfo Kusch, entre otros, ya planteaban en la década de 1970 una filosofía política situada en la realidad latinoamericana. Ya en 1973 acuñaron la categoría de universal situado para caracterizar un estilo de pensamiento filosófico que no renunciaba al horizonte del universal, pero lo redefinía de una manera muy especial. "Creímos que ésa era la ontología (postmetafísica) que requería aquella naciente filosofía de la liberación, en tanto pensamiento que no renunciaba a la caracterización de filosófico; así como sostuvimos que el sujeto de tal filosofía no podía ser el yo de la modernidad eurocéntrica, sino un "nosotros" cultural y latinoamericanamente situado" (Casalla, 2011, p. 9).

En esta misma línea de pensamiento, el filósofo santiagueño Alejandro Auat habla de enfoque situado y lo define como "la asunción consciente del punto de vista desde donde se lee la realidad y de sus opciones gnoseológicas y axiológicas. Esto lleva a primer plano la explicitación del sujeto que investiga y sus compromisos, así como la del "lugar hermenéutico" que privilegia su discurso como respuesta a una previa interpelación de la realidad" (Auat, 2011, p. 30). En este mismo sentido, Víctor Andrés Belaúnde acuñó el término anatopismo para destacar el carácter descontextualizado del pensamiento latinoamericano que simplemente "transplanta" la filosofía occidental al suelo (topos) americano, sin tomar en cuenta la propia realidad y el contexto específico de América Latina (Belaúnde, 1987). Precisamente, el enfoque situado rompe con este anatopismo del que habla Belaúnde.

El enfoque situado también es sostenido por las teóricas del feminismo. Donna Haraway acuñó el concepto de sujeto conocedor situado o conocimiento situado, que es central para la epistemología feminista y es la base de la defensa de la objetividad feminista. Con esta idea la autora rompe con la concepción del sujeto mítico cognoscente universal, único y eterno, tal como lo propone la ciencia moderna, y concibe en cambio un sujetoy un conocimiento marcado por el sexo-género y por circunstancias tales como la etnia, la religión, la clase, las opciones sexuales, entre otras. Esto implica un rechazo absoluto de la visión única del mundo y de la única verdad que se alcanzaría con la ciencia positivista basada en un sujeto de conocimiento ideal que es hombre, moderno, de clase media-alta y europeo o grecolatino. Para la autora el conocimiento refleja las perspectivas particulares del sujeto. Lo que se conoce y cómo se conoce depende de la situación y la perspectiva del sujeto conocedor/a (Haraway, 1995, p. 325).

En este mismo sentido, Sandra Harding (2001) habla de conocimiento situado, en el cual los que producen y reproducen conocimientos están 
históricamente posicionados y localmente situados, no son observadores neutrales, autorizados o situados por fuera y por encima del objeto de conocimiento. Por el contrario, como lo sostiene Donna Haraway (1993), se trata de una epistemología de perspectivas parciales, es decir un intento por construir y transmitir "una mirada amplia desde un lugar particular".

De esta manera, el proceso de formación profesional de los/as Trabajadores/as Sociales no puede darse desde cualquier lugar ni de cualquier manera, sino que tiene que enraizarse, situarse, imbricarse en los contextos específicos latinoamericanos y de cada país y región. Por ejemplo, no es lo mismo analizar la noción de pobreza en Europa que en nuestras tierras, porque los significados son totalmente distintos y también los marcos teóricos que deben utilizarse para el análisis y la interpretación del problema de la pobreza. Lo mismo podríamos decir de muchas otras categorías teóricas y sociales que suelen utilizarse frecuentemente en los procesos de producción de conocimientos, formación y ejercicio profesional, sin ninguna contextualización.

En cuarto lugar, cuando sostengo que es necesario la politización de la formación profesional de los/as Trabajadores/as Sociales, quiero decir que tenemos que recuperar el significado más genuino de la política como toma de posición y búsqueda deliberada de transformación del orden social. El acto de formación es un acto político. De igual manera que las decisiones sobre planes de estudios, perfiles de egresados, contenidos curriculares, programas de asignaturas y selección bibliográfica son también decisiones políticas. Son actos y decisiones políticas porque implican ejercicio del poder, aunque no siempre esto se lleve a cabo de manera visible $y$, además, este ejercicio de poder tiene un direccionamiento que puede ser de búsqueda de transformación social, pero también de mantenimiento y reproducción del orden vigente o de aspiración de regreso a un orden anterior. En cualquiera de estos casos es siempre un hecho político.

Como lo sostengo con Juan Agüero la dimensión político-ideológica es constitutiva del Trabajo Social (Martínez, \& Agüero, 2008), y no hay posibilidad de pensar en alguna transformación del orden social por fuera de la política, ya que ésta es a su vez constitutiva del vivir entre-loshombres, tal comola concibe Hannah Arendt (1997). Si este vivir entre-los-hombres es político, indudablemente la construcción de cualquier orden que deviene de este hecho también es política y por lo tanto esta dimensión siempre está presente, aunque no sea de manera consciente.

Justamente, cuando digo politización de la formación profesional de los/as Trabajadores/as Sociales no estoy diciendo que la política no esté presente, sino que es necesario un proceso de concientización política. Es decir, hacer visible la política como componente central del proceso de formación, mostrar cuál es su sentido, por qué, para quién y para qué de la formación y el ejercicio profesional. Si esto no se hace visible, el ejercicio del poder parece un acto inocente e inocuo cuando en realidad este proceso está totalmente saturado de contenido ideológico y político, ya que la realidad concreta siempre está saturada de múltiples determinaciones, como lo sostiene Karl Marx (1999).

\section{La docencia como compromiso ético}

En este marco, reflexionar sobre la formación profesional en estos tiempos remite a asumir responsabilidades éticas y sociales desde la Universidad Pública. $\mathrm{Si}$ pretendemos que nuestra educación universitaria no sea colonizadora ni una burda reproducción del pensamiento colonizador de los centros de poder, ni una usina de sujetos descontextualizados, que no se identifican ni se apropian del contexto donde se educan y viven, entonces tenemos que pensar en una educación emancipada y emancipadora de los sujetos y en una docencia que implique asumir nuestra responsabilidad ética y política, no sólo 
teniendo en cuenta el contexto en nuestras prácticas educativas, sino involucrándonos en él y sintiéndonos parte de los procesos de cambio.

La ética es una dimensión constitutiva del proceso de enseñanza-aprendizaje. No es posible que la práctica docente pueda ser llevada a cabo sin tener una referencia permanente y consciente de carácter ético, llámese utopía, compromiso, etc. La práctica educativa no puede ser realizada sin un proyecto. Ya lo decía Freire "Lo que me mueve a ser ético por sobre todo, es saber que como la educación es, por su propia naturaleza, directiva y política, yo debo respetar a los educandos, sin jamás negarles mi sueño o mi utopía. Defender una tesis, una posición, una preferencia, con seriedad y con rigor, pero también con pasión, estimulando y respetando al mismo tiempo el derecho al discurso contrario, es la mejor forma de enseñar el derecho a tener derecho de "pelear" por nuestras ideas, por nuestros sueños" (Freire, 1996, p. 74).

La dimensión ético-política de la educación en general es un aspecto bastante invisibilizado, por no decir ignorado, quizás por la pretensión de que la educación debe ser "científica", con todas las connotaciones que el positivismo atribuyó a este término: neutral, a-valorativo, a-histórico, universal, etc.

Los procesos de enseñanzaaprendizaje como práctica política y ética implican al menos a mí entender, los siguientes desafíos:

a) Una mirada crítica capaz de comprender los cambios, la incertidumbre y el conflicto, como componentes constitutivos de la vida social.

b) Una pedagogía de la pregunta, capaz de desterrar, de una vez por todas, el nuevo colonialismo cultural que desea que sigamos repitiendo las respuestas del imperialismo que ellos mismos imponen, consumiendo su cultura en detrimento de la nuestra y repitiendo contenidos, haciendo más eficiente e inclusive intolerable esta educación que Paulo Freire llama "bancaria".

c) Una educación capaz de asumir una función política y una ética liberadora, superando todo vestigio de educación colonial que "forma" imponiendo respuestas a espaldas del pueblo.

d) La popularización del conocimiento científico, es decir la socialización y no la idea de un saber esotérico para unos pocos.

e) La construcción de conocimientos desde una Epistemología Otra.

\section{La docencia como ejercicio de la profesión}

Por último, quiero referirme a un tema que genera polémica hacia el interior del colectivo profesional, aunque para mí no tendría que tener ni siquiera razón de ser. A contrapelo de muchas colegas que sostienen que no es necesario matricularse en sus respectivos colegios porque se desempeñan como docentes y no ejercen la profesión, yo sostengo que la docencia es un ámbito más de ejercicio de la profesión. Algunos colegas ejercen su profesión en el ámbito de la salud, las organizaciones sociales, la justicia, etc. Nosotros, los docentes, ejercemos nuestra profesión en el ámbito de la educación. Lo hacemos en función de pertenecer a una disciplina, de tener un título que dice que somos Licenciados/as en Trabajo Social. Incluso en los perfiles que se especifican para los concursos docentes, se exige como requisito ser Trabajador/a Social.

Ahora bien, el problema se genera cuando escindimos la docencia de la profesión. Cuando nos identificamos sólo cómo docentes y no como Trabajadores/as Sociales. Cuando apelamos y evocamos sólo el título de posgrado por sobre el del grado, siendo que todos/as los/as que accedimos a un título de posgrado, lo pudimos hacer porque tenemos un título de grado.

He aquí la gran paradoja: 
¿Cómo podemos formar profesionales comprometidos con nuestro colectivo profesional, si nosotros mismos no nos sentimos parte de él? ¿Cómo construiremos en nuestros estudiantes sentimientos de pertenencia a nuestras organizaciones profesionales si nosotros mismos nos autoexcluimos? ¿Cómo podemos hablar y educar para un proyecto profesional si nosotros mismos no nos vemos como profesionales?

Tal como lo sostiene José Paulo Netto: "Los proyectos profesionales presentan la autoimagen de una profesión, eligen los valores que legitiman socialmente, delimitan y dan prioridad a sus objetivos y sus funciones, formulan los requisitos teóricos, institucionales y prácticas para su ejercicio, prescriben nomas para el comportamiento de los profesionales y establecen las bases de su relación con los usuarios de sus servicios, con las otras profesiones y con las organizaciones e instituciones sociales privadas y públicas (entre éstas, también y destacadamente con el Estado, al que cabe, históricamente, el reconocimiento jurídico de los estatutos profesionales)" (Netto, 2003, p. 274).

El proyecto profesional y el proyecto ético-político profesional comienzan con la formación y no fuera de ella. Por eso me referí antes a la práctica docente como práctica ético-política. Y por eso también me referí antes a las responsabilidades que esto implica. Si estamos en un lugar privilegiado de formación como la Universidad Pública, si somos trabajadores estatales, con salarios dignos, estabilidad, prestigio, reconocimiento social, etc., esto implica -como contrapartida- mayor carga de responsabilidad y compromiso social y profesional. Es una cuestión de equidad y de justicia social, pero también de consciencia y compromiso histórico con nuestro pueblo.

\section{Consideraciones finales}

Las Universidades Públicas han pasado por muchos derroteros. Como he intentado evidencia en este artículo, han sido siempre un objeto de disputa política e ideológica, un instrumento de poder pensado y utilizado tanto para la liberación y la emancipación como para la dominación y la opresión. Se han construido muchos discursos, que han intentado justificar distintas posiciones, algunas de construcción de proyectos colectivos, de luchas por la liberación y la emancipación, otras de intentos de vaciamiento o de disciplinamiento.

No podemos desvincular a la Universidad Pública de un proyecto de país ni del Proyecto Profesional de Trabajo Social al cual adscribamos. Tampoco podemos desvincularla de la vida social, de las transformaciones sociales y de las necesidades sociales que esto implica. Tampoco podemos reducirla a la mera formación de técnicos y profesionales y menos aún sujetarla a las imposiciones del mercado. Por el contrario, la Universidad Pública tiene hoy más que nunca el deber de formar intelectuales críticos, comprometidos con su tiempo y su realidad histórica.

Creo que en estos tiempos que nos toca vivir como latinoamericanos esta apuesta de repensar la formación profesional de los/as Trabajadores/as y nuestra prácticas docentes como parte del ejercicio profesional desde la dimisión ético-política, es más que pertinente y oportuna que nunca, ya que el Trabajo Social no puede estar ausente de los procesos de, no sólo de vulneración, sino más bien de devastación de Derechos por el que estamos atravesando en Nuestra América producto de las brutales políticas Neoliberales y Neoconservadoras que se están aplicando en nuestros países y que necesariamente implica no sólo una nueva cartografía para el Trabajo Social, sino también nuevas formas de cartografiarlo.

\section{Referencias Bibliográficas}

Arendt, H. (1997). Qué es la política. Barcelona: Paidós.

Auat, A. (2011). Hacia una filosofía política 
situada. Buenos Aires: Waldhuter Editores.

Belaúnde, V. A. (1987). Meditaciones Peruanas. Lima: Edición de la Comisión Nacional del Centenario.

Casalla, M. (2011). Pensar en situación. En A. Auat (Ed.), Hacia una filosofía política situada. Buenos Aires: Waldhuter Editores.

Denzin, N. (2003). Performance Ethnography. Critical pedagogy and politics of culture. New York: Sage Publications.

Freire, P. (1970). La Educación como práctica de la libertad. Montevideo: Tierra Nueva.

Freire, P. (1996). Pedagogía de la Esperanza. Un reencuentro con la Pedagogía del Oprimido. México: Siglo XXI Editores.

Giroux, H. (2003). La inocencia robada. Juventud, multinacionales y política cultural. Madrid: Ediciones Morata.

Haraway, D. (1993). De mujer a género. Buenos Aires: Centro Editor de América Latina.

Haraway, D. (1995). Ciencia, cyborgs y mujeres. La reinvención de la naturaleza. Madrid: Cátedra.
Harding, S. (2001). ¿Existe un método feminista? En E. Bartra (Ed.), Debates en torno a una metodología feminista. México: UNAM.

Martínez, S., \& Agüero, J. (2008). La dimensión político-ideológica del Trabajo Social. Claves para un Trabajo Social emancipador. Buenos Aires: Dunken.

Marx, K. (1999). El capital. Crítica de la economía política. Buenos Aires: Fondo de Cultura Económica.

Netto, J. P. (2003). Servicio Social Crítico. São Paulo, Cortéz.

Salvat (Ed), Encilopedia Salvat. Barcelona: 1972, tomo 9.

Sousa Santos, B. (2009). Una epistemología del Sur: La reinvención del conocimiento y la emancipación social. Buenos Aires: Siglo XXI Editores.

Villarmea, S. (2001). Algunas bases hermenéuticas y epistémicas de la conciencia emancipatoria. Revista de Filosofía, (26).

\section{Sobre el Autor}

Silvana Martínez

Presidenta de la Federación Internacional de Trabajadores Sociales (FITS). Doctora en Ciencias Sociales. Magíster y Licenciada en Trabajo Social. Docente de la Universidad Nacional de Misiones (UNaM). Investigadora Categoría I del Instituto de Estudios Sociales y Humanos CONICET-UNaM. 